\title{
An attempt to improve the solubility and stability of Ocimum tenuiflorum aqueous leaves extract
}

\author{
Rohini, J., Muhammad Ezzudin, R. and *Rabeta, M.S. \\ Food Technology Division, School of Industrial Technology, Universiti Sains Malaysia, 11800 Penang
}

\begin{abstract}
Article history:
Received:4 August 2020

Received in revised form: 9

September 2020

Accepted: 9 November 2020

Available Online: 31 January 2021
\end{abstract}

Keywords:

Solubility,

Stability,

Ocimum tenuiflorum

DOI:

https://doi.org/10.26656/fr.2017.5(1).425

\begin{abstract}
Medicinal plants have gained attention in recent years due to the presence of various bioactive compounds which promote distinct health benefits and is less toxic. However, the plants face common and serious problems due to their active compounds which are the solubility and stability. Ocimum tenuiflorum, one of the ancient medicinal plants were its medicinal values have been widely studies. Yet, study to improve its quality still lacking. Thus, an effort was taken to study and improve the solubility and stability of the plant. Solid dispersions were prepared with extract and different types of surfactants at different ratio have used to improve the stability. Lecithin (1:1 ratio) have improved the solubility significantly $(p<0.05)$ when compared to extract. Enhancement in solubility, hence improved the stability when stored at $4{ }^{\circ} \mathrm{C}$ of the solid dispersion of extract. Overall, the study has successfully improved the quality of the extract with lecithin complex whereby the solubility and increases stability.
\end{abstract}

\section{Introduction}

Herbal medicines have been used worldwide for several decades now on account of the large amounts of active phytoconstituents they contain (Jahan et al., 2016). Medicinal plants are generally characterized with remarkable in vitro properties, but their efficiency in vivo is quite limited because of their low aqueous solubility, lipophilic properties and larger molecular size. These phenomena result in reduced absorption and bioavailability as the active compounds are unable to pass through the cell membrane (Gunasekaran et al., 2014). The term "solubility" should not be confused with the dissolving ability of a substance. According to the Biopharmaceutics Classification System (BCS), the solubility of a drug or compound could be classified as follows: class I - drugs with high solubility and permeability, class II - drugs with low solubility and high permeability, class III - drugs with low solubility and high permeability and class IV - drugs with low solubility and low permeability (Savjani et al., 2012).

Stability issues in natural products pose great concern to researchers. The active compounds of many medicinal plants are prone to degradation, particularly during storage, which also causes a loss of efficacy (Thakur et al., 2011). Scientists have discovered that solubility and stability problems could be solved by inclusion or encapsulation of the target compounds into polymer-like cyclodextrins (CDs). CDs can improve the solubility and stability of various drugs and compounds (Ansari and Parveen, 2016). Besides CDs, phospholipids complexity (PC) can also improve the solubility, stability and permeation of compounds in the form of pharmacosomes (Semalty, 2014).

The genus Ocimum is a member of the Lamiaceae family. Plants from this genus are broadly distributed in most regions worldwide, including tropical, subtropical, and warm regions (Upadhyay et al., 2015). Ocimum tenuiflorum belongs to the genus Ocimum and is commonly known as holy basil in some countries, such as India and Thailand. This aromatic medicinal plant is one of the most promising plants used in Ayurvedic treatments given its natural therapeutic properties (Upadhyay, Nachiappan, and Mishra, 2015). $O$. tenuiflorum contains various biologically potent phytoconstituents, including volatile oils, fatty acids, polysaccharides, and phenolic compounds (Rastogi et al., 2015).

Our recent work on O. tenuiflorum (Rohini et al., 2019) revealed that leaf extracts of this plant have potential pharmacological properties and other researchers for past five years (Parasuraman et al., 2015; Mousavi et al., 2016; Francis et al., 2017), suggest that leaves extract have potential pharmacological properties that could be beneficial for the medical field. Given the 
scarcity of research on the topic, the present study was carried out to improve the solubility and stability of $O$. tenuiflorum leaf extracts, which are known to have various pharmacological properties (Asha et al., 2011; Suanarunsawat et al., 2011; Jeba et al., 2011; Ramteke et al., 2012; Basu et al., 2013) and synergistic effect (Soonthornsit et al., 2017).

\section{Materials and methods}

\subsection{Plant material collection and extraction}

O. tenuiflorum leaves were collected at Perak from the botanical garden, identified and authenticated at School of Biological Sciences, University Sains Malaysia (USM) (Herbarium number is 11400). The leaves collected was preweighed and washed with tap water before dried in the oven at $60^{\circ} \mathrm{C}$ for $24 \mathrm{hrs}$. The dried leaves again weighed and powdered using heavyduty blender. The powdered leaves then extracted with distilled water at a ratio of 1:10 according to the method described by Shetty et al. (2008) with some modification. Extraction was conducted with slight agitation of the sample using orbital shaker at $160 \mathrm{rpm}$ at $27^{\circ} \mathrm{C}$ for $24 \mathrm{hrs}$. The supernatant was collected by centrifuging the mixture at $3500 \mathrm{rpm}$ for $30 \mathrm{mins}$. Finally, dried crude extract of the leaves was obtained by drying the supernatant using an oven at $60^{\circ} \mathrm{C}$.

\subsection{Liquid chromatography-mass spectrometry (LC-MS) screening}

The crude extract of $O$. tenuiflorum leaves was subjected LCMS screening to identify the bioactive compound present in it. The mobile phase used is $0.1 \%$ formic acid in water and acetonitrile (20:80). Injection volume was $2 \mu \mathrm{L}$ at flow rate of $0.3 \mathrm{~mL} / \mathrm{min}$. The total run time was 10 mins. Negative ionization mode was employed with a capillary voltage of $2.5 \mathrm{kV}$ and a source temperature of $200^{\circ} \mathrm{C}$.

\subsection{Selection of wavelength}

Apigenin (API) was chosen as a marker compound based on LCMS screening result in the study. API powder was purchased from MedChemExpress (MCE), USA. About $1 \mathrm{mg}$ accurately weighed and dissolved in $10 \mathrm{~mL}$ of dimethyl sulfoxide (DMSO). The solution was filtered through a $0.45 \mu \mathrm{m}$ nylon filter. Then, about $3 \mathrm{~mL}$ of solution was transferred into glass cuvette and scanned between 300 to $400 \mathrm{~nm}$ using UV spectroscopy model UV-1600 series. ( $\lambda$ max was $340 \mathrm{~nm}$ )

\subsection{High performance liquid chromatography (HPLC) setting}

The HPLC condition was set up as per Raghu and
Agrawal (2016) with slight modifications. The modified method was then validated as per ICH standard guideline (Guideline, 2005) for its linearity, selectivity, the limit of detection (LOD), limit of quantification (LOQ), accuracy, and precision before starting solubility test.

RP Waters, 2487 dual $\lambda$ absorbance detector with Symmetry ${ }^{\circledR}$ C18 column $(5.0 \mu \mathrm{m} \times 4.6 \mathrm{~mm} \times 250 \mathrm{~mm})$ was used as the HPLC apparatus. Acetonitrile and $0.1 \%$ trifluoroacetic acid in deionized water mixed at a ratio of 40:60 were used as the binary mobile phase. The mobile phase was degassed for $5 \mathrm{~min}$ and filtered through a 0.45 $\mu \mathrm{m}$ nylon filter. The chromatographic conditions were as follows: flow rate of $1.0 \mathrm{~mL} / \mathrm{min}$ flow rate, injection volume of $20 \mu \mathrm{L}$, a column temperature of $25^{\circ} \mathrm{C}$, and detector wavelength of $340 \mathrm{~nm}$. The analysis was performed through isocratic elution with the total run time of 10 mins.

\subsection{Standard preparation}

About $1 \mathrm{mg}$ of the standard API powder was accurately weighed and dissolved in $10 \mathrm{~mL}$ of DMSO to prepare the stock solution $(100 \mu \mathrm{g} / \mathrm{mL})$. Different concentrations of working solutions $(50,25,12.5,6.25$, $3.13,1.56$ and $0.78 \mu \mathrm{g} / \mathrm{mL}$ ) were prepared through serial dilution from the stock solution. The standard solution was filtered through a $0.45 \mu \mathrm{m}$ nylon filter into vials. The calibration curve was plotted as the concentration of standard versus peak area response.

\subsection{Evaluation of system suitability}

System suitability was evaluated by injecting six replicates of the standard solution at the concentration of $50 \mu \mathrm{g} / \mathrm{mL}$. Chromatograms were obtained. The accepted relative standard deviation (RSD) for the retention time and the peak area of the replicate injection should exceed $2.0 \%$.

\subsection{HPLC method validation}

\subsubsection{Linearity}

The linearity of the method was analyzed by injecting the standard solution at eight different concentrations $(100 \mu \mathrm{g} / \mathrm{mL}$ to $0.78 \mu \mathrm{g} / \mathrm{mL})$. The calibration graph was plotted as the standard concentration versus the peak area response. Linearity was calculated through the least-squares regression method.

\subsubsection{Selectivity}

A placebo solution was prepared per test solution and injected into the HPLC system under the test conditions. The presence of any interfering peak at the retention time of API was determined. 


\subsubsection{LOD and $L O Q$}

The limit of detection (LOD, signal-to-noise ratio of 3 ) is the lowest amount of analyte that can be detected. The limit of quantification LOQ, signal-to-noise ratio of 10 ) is the lowest amount of analyte that can be quantified with acceptable accuracy and precision. LOD and LOQ were evaluated using the following formulas: $\mathrm{LOD}=3.3$ $\times \mathrm{SD} / \mathrm{S}$ and $\mathrm{LOQ}=10 \times \mathrm{SD} / \mathrm{S}$, where $\mathrm{SD}$ is the standard deviation of the response (peak area), and $S$ is the slope of the calibration curve.

\subsubsection{Precision}

The intra- and interday precisions of the system and method were evaluated. A total of six replicates of the standard were injected at the concentration of $50 \mu \mathrm{g} / \mathrm{mL}$ on the same day for the measurement of intraday precision $(n=3)$. Nine replicates of the standard were injected over 3 consecutive days $(n=9)$ for the measurement of interday precision. RSD values were calculated.

\subsubsection{Accuracy}

The accuracy of the method was analyzed by calculating API recovery from spiked samples. Sample solutions were spiked with a known amount of the standard at 25, 50 and $100 \%$. The spiking test was carried out in triplicate, and the recovery amount was expressed in mean percentage.

\subsection{Preparation of solid dispersion}

The solid dispersions of extract were done using the solvent evaporation method according to Wang et al. (2013). Three different types of surfactants, beta cyclodextrin (BCD), hydroxyl-beta cyclodextrin (h$\mathrm{BCD}$ ) and soy lecithin (LCT) were used to prepared the solid dispersions of extract. The extract and surfactant at ratio $1: 1$ and $1: 2$ were prepared by physical mixture using $30-70 \%$ ethanol until complete dissolution. The solutions beakers were closed and allowed to mix until equilibrium was reached for about 3-4 hrs with agitation at $90 \mathrm{rpm}$ in an orbital shaker.

\subsection{Solubility test}

About 5-50 mg of extract, solid dispersions 1:1 and 1:2 were weighed and dissolved in $1 \mathrm{~mL}$ of distilled water respectively. All the samples were sonicated at $45^{\circ}$ $\mathrm{C}$, frequency of $60 \mathrm{kHz}$ for a while to ensure complete dissolution. Then, the samples were filtered into HPLC vials using a $0.45 \mu \mathrm{m}$ syringe filter. The test was run as per modified and validated HPLC condition mention in section 2.4 .

\subsection{Storage stability study}

Storage stability was studied after improvement of extract solubility has done. One type of solid dispersions was chosen based on the solubility test. The stability study was done with comparison to the extract for 8 weeks considering API as a marker compound. In this study, two forms of the extract and solid dispersions which are the dry and liquid form was evaluated for its stability. All the samples were stored in three different temperatures, room temperature, $3-6^{\circ} \mathrm{C}$ and $43-47^{\circ} \mathrm{C}$ with a relative humidity of $72 \pm 3 \%$. The content of API in all the samples was quantified using HPLC method (Brinda and Tanuja, 2015) with slight modification.

\subsection{Statistical analysis}

All the data were analyzed using one-way ANOVA and Tukey multiple range test with SPSS software version 20. Data were plotted as mean \pm standard error mean (SEM) and $\mathrm{p}<0.05$ is considered statistically significant.

\section{Results and discussion}

\subsection{LCMS screening of aqueous leaves extract}

Table 1 shows the list of compounds that were detected in LCMS screening using aqueous leaves extract of $O$. tenuiflorum. The screening proved that the extract contained compounds from sugar, flavonoids, ester, lipid and others.

Table 1. LCMS screening of Ocimum tenuiflorum aqueous leaves extract

\begin{tabular}{ccc}
\hline Compound name & $\begin{array}{c}\text { Retention time } \\
\text { (RT) }\end{array}$ & Mass \\
\hline Glyceraldehyde & 0.4036 & 90.032 \\
Propionylglycine methyl ester & 0.4064 & 145.0736 \\
p-Hydroxymandelic acid & 0.4173 & 168.0426 \\
PS(21:0/18:3(6Z,9Z,12Z)) & 0.4183 & 827.5626 \\
epi-4'-hydroxyjasmonic acid & 0.4194 & 226.1207 \\
Apigenin & 0.4245 & 270.0532 \\
Erythrono-1,4-lactone & 0.4267 & 118.0269 \\
7,8-Dihydroxycoumarin & 0.4275 & 178.0272 \\
p-Salicylic acid & 0.4302 & 138.0319 \\
trihydroxy-octadecadienoic acid & 0.4311 & 328.2251 \\
Fisetin & 0.4343 & 286.0483 \\
DL-3-hydroxy caproic acid & 0.4373 & 132.0793 \\
Phenyl acetate & 0.4375 & 136.0527 \\
3-propylmalic acid & 0.4473 & 176.0682 \\
Orthothymotinic Acid & 0.4822 & 194.0942 \\
6-Gingerol & 0.4998 & 294.1821 \\
\hline
\end{tabular}

O. tenuiflorum has been a promising plant since decades ago in treatment of various illness (Suanarunsawat et al., 2011) especially the leaves of the 
plant where it helps to resolve most of the health issues such as fever, cough, pain, skin diseases and many more (Lahon and Das, 2011). Since the benefits of leaves have been proved traditionally and scientifically, it is important to explore deeper with the leaves. This study was conducted in order to improve the solubility and stability of the plant leaves extract for better improvement of its biological properties.

\subsection{Selection of wavelength}

Figure 1 shows the UV absorbance spectra of API whereby the maximum absorbance was observed at the wavelength of $340 \mathrm{~nm}$. Thus, this wavelength was selected for further studies using HPLC method.

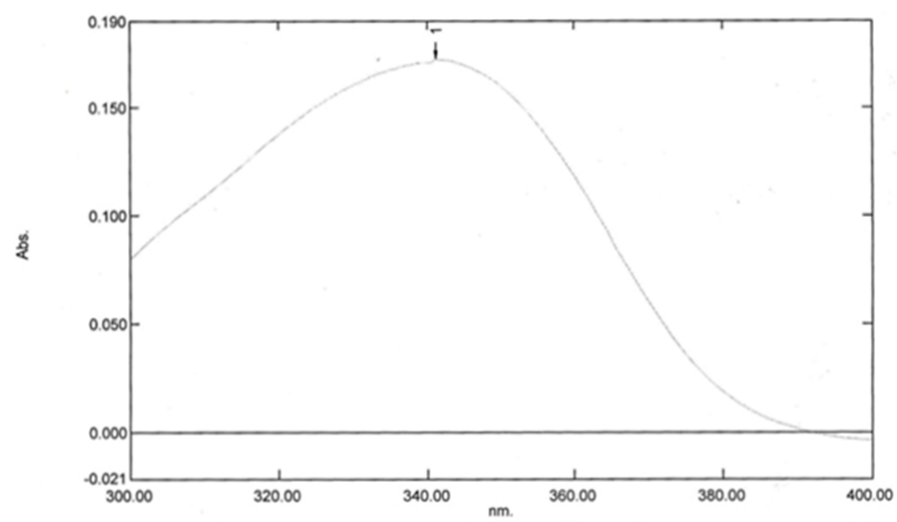

Figure 1. Peak for maximum UV absorbance spectra of API

\subsection{System suitability}

The HPLC system suitability was evaluated by injecting six replicates of $50 \mu \mathrm{g} / \mathrm{mL}$ of API standard solution. The acceptance criterion should not be more than $2 \%$ RSD for the retention time and peak area. The results are shown in Table 2.

Table 2. System suitability study

\begin{tabular}{lcc}
\hline & Retention Time $(\min )$ & Peak Area $(\mathrm{mV} . \mathrm{s})$ \\
\hline Mean $(\mathrm{n}=6)$ & 8.472 & 4242.664 \\
SD & 0.09 & 72.12 \\
RSD (\%) & 1.07 & 1.70 \\
\hline
\end{tabular}

As preferred by many, oral administration is the most convenient and easy route of administration among other routes (Rabti et al., 2014). Solubility is an important factor associated with absorption of compounds that were administered orally. Appropriate solubility in gastrointestinal fluid and permeation through cell membranes is necessary for proper absorption of administered substances (Yousaf et al., 2018).

According to Jahan et al. (2016), phytochemicals of medicinal plants have relatively low absorption and bioavailability. In this study, the LCMS screening of $O$. tenuiflorum aqueous extract revealed that it contains compounds from varieties of groups like flavonoids, lipids, ester, sugars and others. Thus, it was necessary to improve the solubility of the extract in order to enhance its absorption and bioavailability. Numbers of techniques have been utilized by researchers for the improvement of solubility like inclusion complex (Canbolat et al., 2014; Mangolim et al., 2014; Qiu et al., 2014), micronization (Rasenack and Müller, 2002; Bansal et al., 2011; Khadka et al., 2014) hydrotrophy (Agrawal et al., 2004; Kim et al., 2010; Abraham et al., 2014), solid dispersion (Patel et al., 2008; Sinha et al., 2010; Tran et al., 2013).

\subsection{HPLC method validation}

\subsubsection{Linearity}

The calibration curve plotted for eight concentrations of the standard over peak area response indicate the linearity of the method with correlation coefficient $\left(\mathrm{R}^{2}\right)$ equals to 0.9998 . The regression analysis is shown in Figure 2.

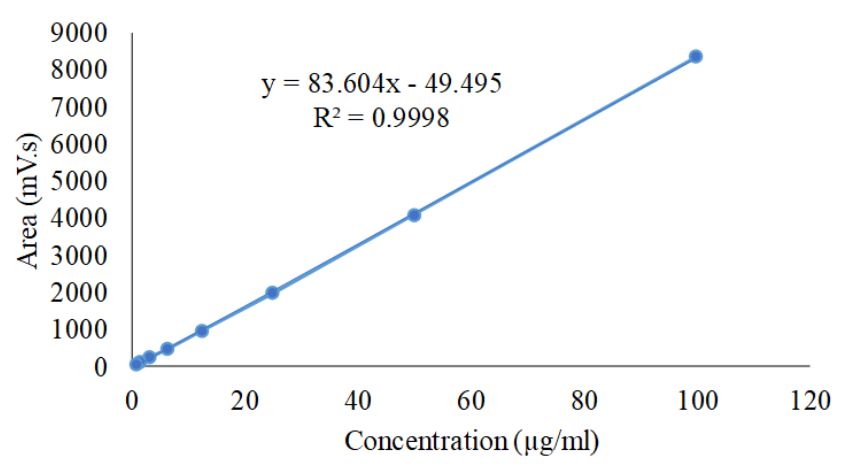

Figure 2. Calibration curve of the standard

\subsubsection{Selectivity}

Based on Figure 3 and 4, it shows that the system is highly specific and selective as no interfering peak was eluted at the retention time of API.

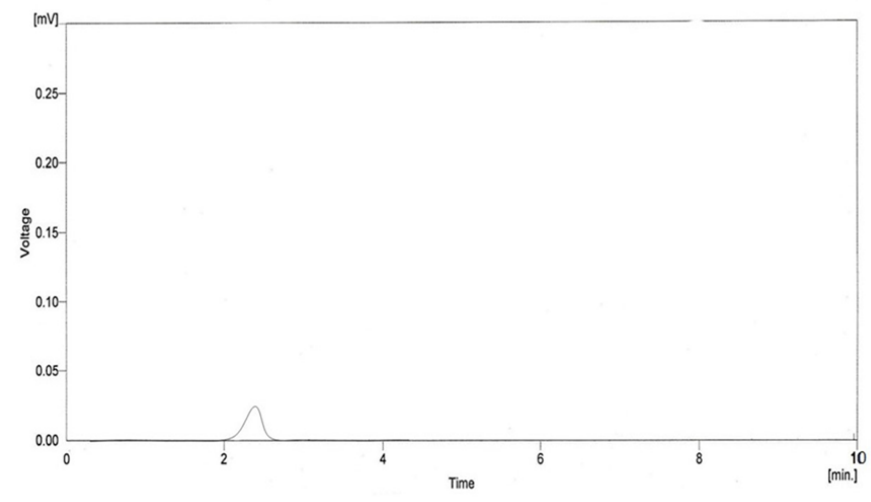

Figure 3. Chromatogram of blank solution

\subsubsection{LOD and $L O Q$}

LOD and LOQ values were calculated on the basis of a linear graph equation. The LOD and LOQ values of the triplicate sample injections were 0.034 and $0.102 \mu \mathrm{g} /$ $\mathrm{mL}$ respectively. 


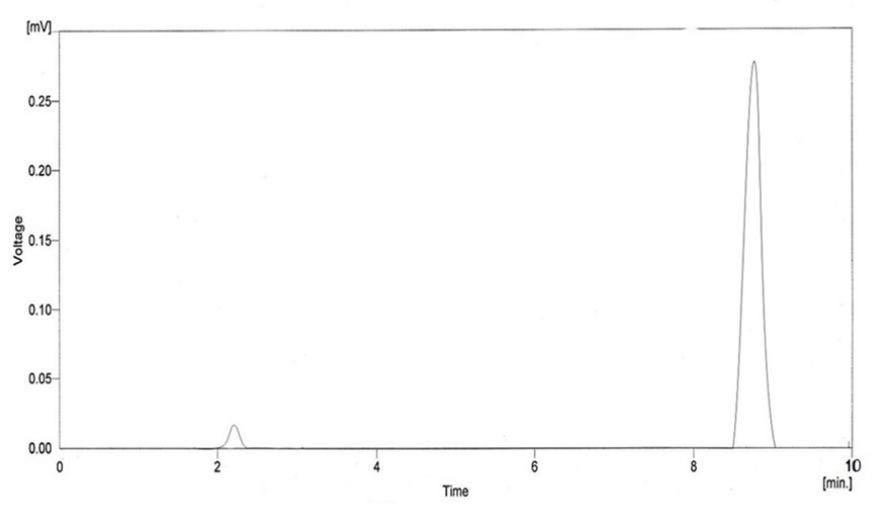

Figure 4. Chromatogram of the standard solution. The acceptance criterion is whereby the RSD \% value is below $2 \%$. The percentages of recovery of all three levels were in the range of 101.3 to $101.8 \%$.

\subsubsection{Precision}

The results of inter- and intraday precision measurements of the developed method are listed in Table 3. The acceptable criterion for the precision of the HPLC method is RSD $<2 \%$. The proposed system provided $\mathrm{RSD} \%$ values of less than $<2 \%$ for both interand intraday measurements. These results suggest that the proposed system could precisely measure API.

Table 3. Peak areas of three replicates injection of standard $(50 \mu \mathrm{g} / \mathrm{mL})$

\begin{tabular}{cccc}
\hline & Day 1 & Day 2 & Day 3 \\
\hline 1 & 4178.803 & 4312.207 & 4083.187 \\
2 & 4196.078 & 4326.561 & 4097.964 \\
3 & 4183.995 & 4318.475 & 4088.223 \\
Mean & 4186.292 & 4319.081 & 4089.791 \\
SD & 8.864 & 7.196 & 7.512 \\
RSD \% & 0.212 & 0.167 & 0.184 \\
\hline
\end{tabular}

\subsubsection{Accuracy}

The accuracy of the method was analyzed at three levels which are 25,50 and $100 \%$. The result was presented in Table 4 . The recovery of the analyte found to be below the acceptance criterion whereby the RSD \% value is below $2 \%$. The percentages of recovery of all three levels were in the range of 101.3 to $101.8 \%$.

Table 4. Recovery percentage of three replicates injection of standard at three levels

\begin{tabular}{cccc}
\hline & $25 \%$ & $50 \%$ & $100 \%$ \\
\hline RSD & 0.38 & 0.21 & 0.11 \\
Recovery $\%$ & 101.86 & 101.33 & 101.59 \\
\hline
\end{tabular}

\subsection{Solubility test}

Figure 5 shows the solubility test results of solid dispersions from three different types of surfactants compared with that of the original leaf extract. Extract solubility was significantly $(\mathrm{p}<0.05)$ improved by using lecithin at 1:1 ratio compared with other types and the ratio of surfactants $(\mathrm{p}>0.05)$.

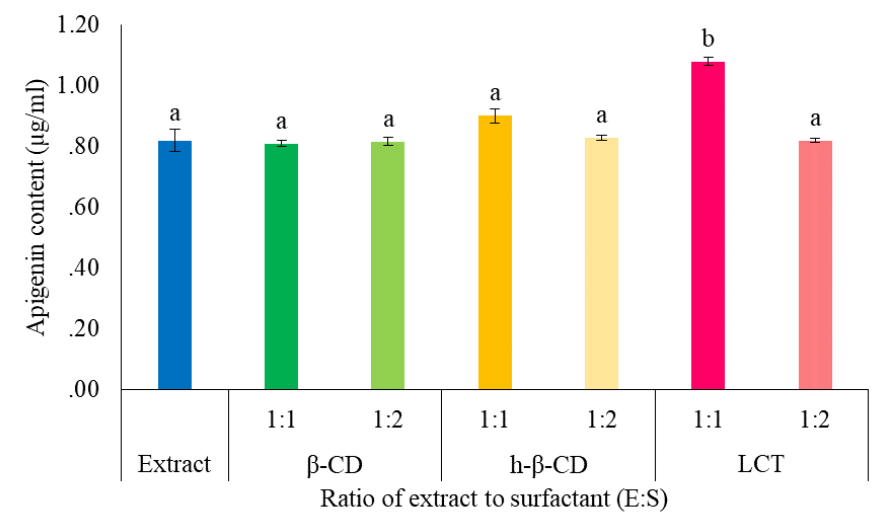

Figure 5. Solubility test of extract and SDs (1:1 and 1:2). Vertical bars represent the standard error mean $(n=3)$. Bars with different alphabets are statistically significant when $(p<0.05)$.

Although oral delivery is the preferred administration route for many herbal medicines, this method often reduces the bioavailability of the administered compounds. According to Gonçalves et al. (2016), poor aqueous solubility is amongst the main reasons behind the low bioavailability of active compounds after oral administration. Thus, improvements in solubility may also be expected to improve the bioavailability of target compounds after administration.

Amongst the available approaches for solubility enhancement, solid dispersion is one of the most widely used (Kommavarapu et al., 2015). Solid dispersions of poorly soluble compounds could be achieved via melting, kneading, solvent evaporation and lyophilization. Solvent evaporation is an excellent technique to enhance the solubility and dissolution rate of various compounds (Yousaf et al., 2018).

The solubility test of solid dispersion $O$. tenuiflorum aqueous leaves extract was performed using HPLC equipment. The HPLC setting has been slightly modified and validated to reduce the time consumption for each run. The method developed and validated by (Raghu and Agrawal, 2016), requires a total run time of 40 mins for API separation through isocratic elution. By contrast, the proposed method required a total run time of 10 mins for API separation through isocratic elution. The modified method was validated and optimized with a linearity of $\mathrm{R}^{2}=0.9998$ for different standard concentrations (100$0.78 \mu \mathrm{g} / \mathrm{mL}$ ). The proposed system is highly suitable for API detection given that it provided a $\mathrm{RSD} \%$ of $<2 \%$. The system is highly selective for API because no 
interfering peak can be observed at the retention time of the standard solution. The system presented satisfactory LOD and LOQ values of 0.034 and $0.102 \mu \mathrm{g} / \mathrm{mL}$ respectively, with acceptable ranges of accuracy and precision below the RSD of $2 \%$. Hence, this method was followed for solubility and storage stability in this study.

The solubility of $O$. tenuiflorum aqueous leaf extract was successfully enhanced by adopting lecithin at a ratio of 1:1 using the solvent evaporation-based solid dispersion method. Improvements in extract solubility may be attributed to the molecular structure of lecithin, which features amphipathic owning the amphipathic property as stated by Wang et al. (2013). Lecithin molecules are arranged in the form of bilayer sheets that allow the attachment of hydrophilic and hydrophobic compounds (Saraf, 2010). Similar to lecithin, CD derivatives, such as BCD and h-BCD, have also have been proven to improve the solubility of poorly soluble compounds (Yuvaraja and Khanam, 2014; Zhao et al., 2016). However, in this study, the solubility of the extracts could not be enhanced by the $\mathrm{CD}$ derivatives, likely because of the unique structure of $\mathrm{CD}$. CDs are cyclic polymers composed of a hydrophobic interior and hydrophilic exterior that form a cone-shaped structure. This type of structure limits the loading of a compound either small or larger in size (Miranda et al., 2011). Semalty (2014) said that higher CD ratios (e.g., 1:3, 1:4 and so on) are required to improve the solubility of larger compounds, especially those from medicinal plants.

\subsection{Stability study}

Figures 6, 7 and 8 show the stability of extract and solid dispersions of the extract with lecithin 1:1 ratio (dry and liquid). Figure 6 and 7 show a similar trend of API degradation whereby $0 \%$ of API content was available in liquid-solid dispersions, liquid and dry extract samples while 98\% API content available in dry solid dispersions during the $2^{\text {nd }}$ weeks of study. After 2 weeks, the API in the dry solid dispersions was rapidly degraded, and $0 \%$ API was available in the $4^{\text {th }}$ and $8^{\text {th }}$ weeks of the study. Changes in API content in Figure 8 are similar to those in Figure 6 and 7. Specifically, $0 \%$ API was available in the dry and liquid extracts by the $2^{\text {nd }}$ week of the study. When the liquid-solid dispersions were stored at $4^{\circ} \mathrm{C}$, however, remarkable changes in API degradation were observed. Specifically, API remained available up to the $4^{\text {th }}$ week of the study. Indeed, approximately $90 \%$ of the API content of the liquid-solid dispersions remained available up to the $8^{\text {th }}$ week when stored at $4^{\circ} \mathrm{C}$.

The loss of active compounds during storage is an important factor that should be considered in evaluating the quality of natural products (Thakur et al., 2011).
Active compounds are also highly susceptible to degradation or breakdown into inactive by-products in the circulation, which reduces their bioavailability (Coimbra et al., 2011). Because the LCMS result of the $O$. tenuiflorum aqueous leaf extract confirms that it is made up of various compounds, the stability of this extract must be assessed. Thus, the storage stability and bioavailability (in vitro drug release) of the extract were studied after its solubility was improved with lecithin at a 1:1 ratio.

The stability of the solid dispersions compounds was stable and remained available about $90 \%$ in dry form at $4^{\circ} \mathrm{C}$, by referring API as a marker compound. Compared with the original extract, solid dispersion compounds with lecithin demonstrated enhanced stability. Improvement in the stability of the solid dispersions compared with that of the extract may be due to the formation of a coating on the former during lecithin complexation was prepared (Kumar et al., 2014). This coating prevents the leakage of active compounds during storage (Semalty, 2014). However, the stability of solid dispersion compounds stored at room temperature and $45^{\circ} \mathrm{C}$ could not be maintained by lecithin complexation because lecithin is sensitive to heat (Wang et al., 2014).

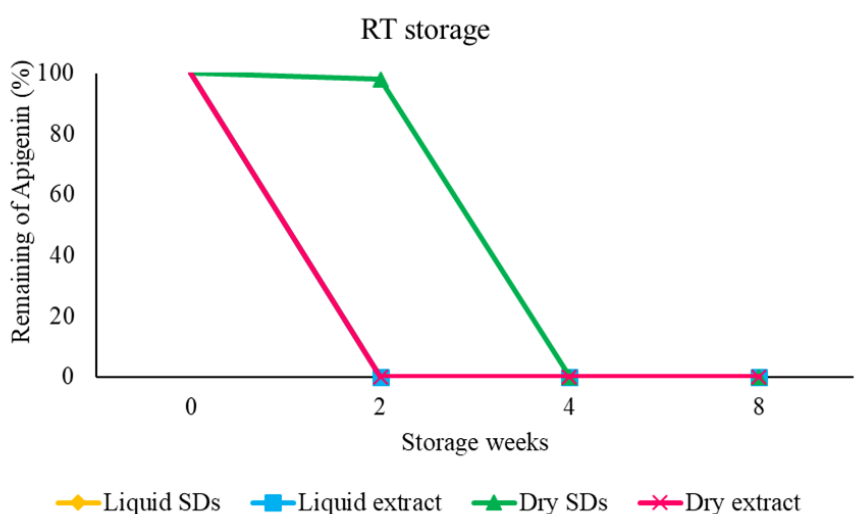

Figure 6. Stability of the extract and SDs samples stored at RT.

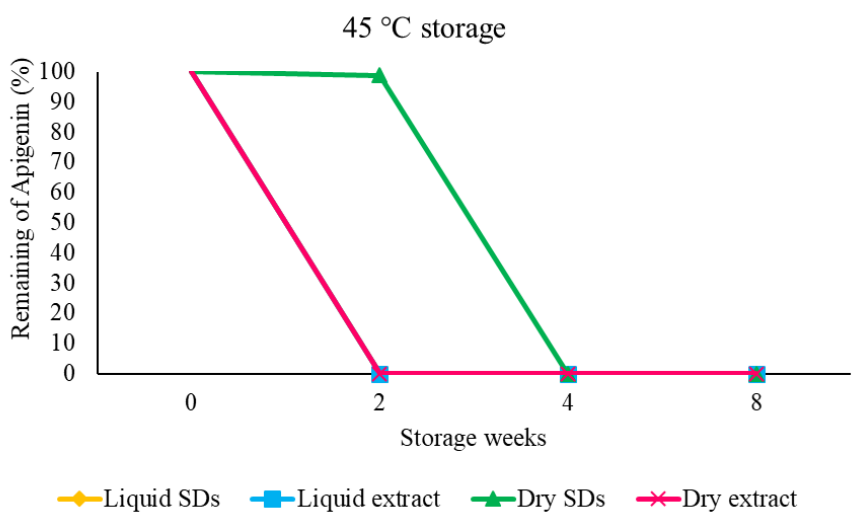

Figure 7. Stability of the extract and SDs samples stored at $45^{\circ}$ C 


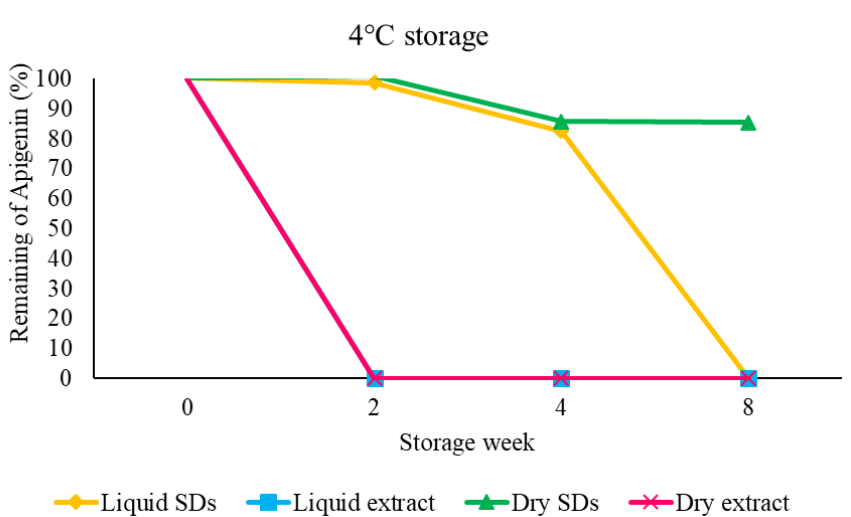

Figure 8 . Stability of the extract and SDs samples stored at $4^{\circ}$ C

\section{Conclusion}

This study proved that $O$. tenuiflorum aqueous leaf extracts are poorly soluble because of the various types of compounds they contain. The compounds present in these extracts are not stable in dry or liquid form during storage and have poor dissolution properties. In this work, we improved the solubility of $O$. tenuiflorum aqueous leaf extracts via the solid dispersion method. The solubility of the extracts was successfully enhanced by lecithin complexation, and the stability of the compound in the dry solid dispersion sample was prolonged during storage at $4^{\circ} \mathrm{C}$.

\section{Acknowledgments}

This work funded by a grant of Universiti Sains Malaysia RU (1001/PTEKIND/ 812176) and AUPI00249 grants contributed to the funding of this research. The financial support for GA scheme from Universiti Sains Malaysia for co-author Rohini Jayaraman was gratefully acknowledged.

\section{References}

Abraham, S., Deveswaran, R., Furtado, S., Bharath, S. and Madhavan, V. (2014). Application of Hydrotropic Solubilization in Spectrophotometric Estimation of Lornoxicam from Tablets. International Scholarly Research Notices, 2014, 810128. https://doi.org/10.1155/2014/810128

Agrawal, S., Pancholi, S., Jain, N. and Agrawal, G. (2004). Hydrotropic solubilization of nimesulide for parenteral administration. International Journal of Pharmaceutics, 274(1-2), 149-155. https:// doi.org/10.1016/j.ijpharm.2004.01.012

Ansari, M. and Parveen, R. (2016). Solubility and stability enhancement of curcumin: Improving drug properties of natural pigment. Drug Development and Therapeutics, 7, 113-116. https:// doi.org/10.4103/2394-6555.191166
Asha, B., Nagabhushan, A. and Shashikala, G. (2011). Comparative study of wound healing activity of topical and oral Ocimum sanctum linn in albino rats. Al Ameen Journal of Medical Science, 4(4), 309-314.

Bansal, K., Pant, P., Rao, P., Padhee, K., Sathapathy, A. and Kochhar, P.S. (2011). Micronization and dissolution enhancement of norethindrone. International Journal of Research in Pharmacy and Chemistry, 1(3), 315-319.

Basu, A., Mitra, E., Mukherjee, D., Ghosh, A.K., Firdaus, S.B., Ghosh, D., Chattopadhyay, A., Pattari, S.K., Dutta, S. and Jana, K. (2013). Aqueous tulsi leaf (Ocimum sanctum 1.) extract protects against piroxicam-induced gastric ulceration in rats: involvement of antioxidant mechanisms. International Journal of Pharmacy and Pharmaceutical Sciences, 5(Suppl. 1), 438-447.

Brinda, S. and Tanuja, N. (2015). Formulation, characterization and evaluation of herbal under-eye cream. World Journal of Pharmaceutical Science, 3 (3), 542-552.

Canbolat, M.F., Celebioglu, A. and Uyar, T. (2014). Drug delivery system based on cyclodextrinnaproxen inclusion complex incorporated in electrospun polycaprolactone nanofibers. Colloids and Surfaces B: Biointerfaces, 115, 15-21. https:// doi.org/10.1016/j.colsurfb.2013.11.021

Coimbra, M., Isacchi, B., van Bloois, L., Torano, J.S., Ket, A., Wu, X., Broere, F., Metselaar, J.M., Rijcken, C.J. and Storm, G. (2011). Improving solubility and chemical stability of natural compounds for medicinal use by incorporation into liposomes. International Journal of Pharmaceutics, 416(2), 433-442. https://doi.org/10.1016/ j.ijpharm.2011.01.056

Francis, N.K., Pawar, H.S., Peter, N., Biswas, G., Majumdar, J., Mitra, A. and Mitra, A. (2017). Evaluation of wound healing and antimicrobial physiognomies of alcoholic extract of Ocimum sanctum (basil) in diabetic rabbit model. International Journal of Herbal Medicine, 5(2, Part B), 91-97.

Gonçalves, L., Maestrelli, F., Mannelli, L.D.C., Ghelardini, C., Almeida, A. and Mura, P. (2016). Development of solid lipid nanoparticles as carriers for improving oral bioavailability of glibenclamide. European Journal of Pharmaceutics and Biopharmaceutics, 102, 41-50. https:// doi.org/10.1016/j.ejpb.2016.02.012

Guideline, I.H.T. (2005). Validation of analytical procedures: text and methodology Q2 (R1). Paper presented at the International Conference on Harmonization. Geneva, Switzerland. 
Gunasekaran, T., Haile, T., Nigusse, T. and Dhanaraju, M.D. (2014). Nanotechnology: an effective tool for enhancing bioavailability and bioactivity of phytomedicine. Asian Pacific Journal of Tropical Biomedicine, 4(Suppl. 1), S1-S7. https:// doi.org/10.12980/APJTB.4.2014C980

Jahan, N., Aslam, S., Rahman, K.U., Fazal, T., Anwar, F. and Saher, R. (2016). Formulation and characterisation of nanosuspension of herbal extracts for enhanced antiradical potential. Journal of Experimental Nanoscience, 11(1), 72-80. https:// doi.org/10.1080/17458080.2015.1025303

Jeba, C., Vaidyanathan, R. and Rameshkumar, G. (2011). Immunomodulatory activity of aqueous extract of Ocimum sanctum in rat. International Journal on Pharmaceutical and Biomedical Research, 2(1), 33-38.

Khadka, P., Ro, J., Kim, H., Kim, I., Kim, J.T., Kim, H., Cho, J.M., Yun, G. and Lee, J. (2014). Pharmaceutical particle technologies: An approach to improve drug solubility, dissolution and bioavailability. Asian Journal of Pharmaceutical Sciences, 9(6), 304-316. https://doi.org/10.1016/ j.ajps.2014.05.005

Kim, J.Y., Kim, S., Papp, M., Park, K. and Pinal, R. (2010). Hydrotropic solubilization of poorly watersoluble drugs. Journal of Pharmaceutical Sciences, 99(9), 3953-3965. https://doi.org/10.1002/jps.22241

Kommavarapu, P., Maruthapillai, A., Palanisamy, K. and Sunkara, M. (2015). Preparation and characterization of rilpivirine solid dispersions with the application of enhanced solubility and dissolution rate. Beni-Suef University Journal of Basic and Applied Sciences, 4 (1), 71-79. https://doi.org/10.1016/ j.bjbas.2015.02.010

Lahon, K. and Das, S. (2011). Hepatoprotective activity of Ocimum sanctum alcoholic leaf extract against paracetamol-induced liver damage in Albino rats. Pharmacognosy Research, 3(1), 13-18. https:// doi.org/10.4103/0974-8490.79110

Mangolim, C.S., Moriwaki, C., Nogueira, A.C., Sato, F., Baesso, M.L., Neto, A.M. and Matioli, G. (2014). Curcumin- $\beta$-cyclodextrin inclusion complex: stability, solubility, characterisation by FT-IR, FTRaman, X-ray diffraction and photoacoustic spectroscopy, and food application. Food Chemistry, 153, 361-370. https://doi.org/10.1016/ j.foodchem.2013.12.067

Miranda, J.C.D., Martins, T.E.A., Veiga, F. and Ferraz, H.G. (2011). Cyclodextrins and ternary complexes: technology to improve the solubility of poorly soluble drugs. Brazilian Journal of Pharmaceutical
Sciences, 47, 665-681. https://doi.org/10.1590/S1984 $-82502011000400003$

Mousavi, L., Salleh, R.M., Murugaiyah, V. and Asmawi, M.Z. (2016). Hypoglycemic and anti-hyperglycemic study of Ocimum tenuiflorum L. leaves extract in normal and streptozotocin-induced diabetic rats. Asian Pacific Journal of Tropical Biomedicine, 6 (12), 1029-1036. https://doi.org/10.1016/ j.apjtb.2016.10.002

Parasuraman, S., Balamurugan, S., Christapher, P.V., Petchi, R.R., Yeng, W.Y., Sujithra, J. and Vijaya, C. (2015). Evaluation of antidiabetic and antihyperlipidemic effects of hydroalcoholic extract of leaves of Ocimum tenuiflorum (Lamiaceae) and Prediction of Biological Activity of its Phytoconstituents. Pharmacognosy Research, 7(2), 156-165. https://doi.org/10.4103/0974-8490.151457

Patel, M., Tekade, A., Gattani, S. and Surana, S. (2008). Solubility enhancement of lovastatin by modified locust bean gum using solid dispersion techniques. AAPS PharmSciTech, 9, 1262-1269. https:// doi.org/10.1208/s12249-008-9171-4

Qiu, N., Cheng, X., Wang, G., Wang, W., Wen, J., Zhang, Y., Song, H., Ma, L., Wei, Y. and Peng, A. (2014). Inclusion complex of barbigerone with hydroxypropyl- $\beta$-cyclodextrin: preparation and in vitro evaluation. Carbohydrate Polymers, 101, 623630. https://doi.org/10.1016/j.carbpol.2013.09.035

Rabti, H., Salmani, J.M.M., Elamin, E.S., Lammari, N., Zhang, J. and Ping, Q. (2014). Carbamazepine solubility enhancement in tandem with swellable polymer osmotic pump tablet: A promising approach for extended delivery of poorly water-soluble drugs. Asian Journal of Pharmaceutical Sciences, 9(3), 146 -154. https://doi.org/10.1016/j.ajps.2014.04.001

Raghu, M. and Agrawal, P. (2016). Analytical Method Development and Validation By HPLC For The Determination of Apigenin in Justicia Gendarussa. World Journal of Pharmacy and Pharmaceutical Sciences, 5(8), 1053-1066.

Ramteke, C., Chakrabarti, T., Sarangi, B.K. and Pandey, R.-A. (2012). Synthesis of silver nanoparticles from the aqueous extract of leaves of Ocimum sanctum for enhanced antibacterial activity. Journal of Chemistry, 2013, 278925. https:// doi.org/10.1155/2013/278925

Rasenack, N. and Müller, B.W. (2002). Dissolution rate enhancement by in situ micronization of poorly water-soluble drugs. Pharmaceutical Research, 19, 1894-1900. https://doi.org/10.1023/ 
Rastogi, S., Kalra, A., Gupta, V., Khan, F., Lal, R.K., Tripathi, A.K., Parameswaran, S., Gopalakrishnan, C., Ramaswamy, G. and Shasany, A.K. (2015). Unravelling the genome of Holy basil: an "incomparable"“elixir of life" of traditional Indian medicine. BMC Genomics, 16, 413. https:// doi.org/10.1186/s12864-015-1640-z

Rohini, J., Mansoureh, N.V., Fouad Saleih, R.A.-S., Rabeta, M.S. and Amin Malik Shah, A.M. (2019). Preliminary screening on wound healing potential of Ocimum tenuiflorum 1. using in vitro assays. Food Research, 3(3), 258 - 264. https://doi.org/10.26656/ fr.2017.3(3).010

Saraf, S. (2010). Applications of novel drug delivery system for herbal formulations. Fitoterapia, 81(7), 680-689. https://doi.org/10.1016/j.fitote.2010.05.001

Savjani, K.T., Gajjar, A.K. and Savjani, J.K. (2012). Drug solubility: importance and enhancement techniques. ISRN Pharmaceutics, 2012, 195727. https://doi.org/10.5402/2012/195727

Semalty, A. (2014). Cyclodextrin and phospholipid complexation in solubility and dissolution enhancement: a critical and meta-analysis. Expert Opinion on Drug Delivery, 11(8), 1255-1272. https:// doi.org/10.1517/17425247.2014.916271

Shetty, S., Udupa, S. and Udupa, L. (2008). Evaluation of antioxidant and wound healing effects of alcoholic and aqueous extract of Ocimum sanctum Linn in rats. Evidence-Based Complementary and Alternative Medicine, 5, 428796. https://doi.org/10.1093/ecam/ nem004

Sinha, S., Ali, M., Baboota, S., Ahuja, A., Kumar, A. and Ali, J. (2010). Solid dispersion as an approach for bioavailability enhancement of poorly watersoluble drug ritonavir. AAPS Pharmscitech, 11, 518527. https://doi.org/10.1208/s12249-010-9404-1

Soonthornsit, N., Hemstapat, W., Pitaksutheepong, C. and Tasana, P. (2017). Enhancement of stability, release and in vitro digestibility of mulberry stem extract using microemulsions. International Journal of Pharmacy and Pharmaceutical Sciences, 9(7), 103-109. https://doi.org/10.22159/ ijpps.2017v9i7.18609

Suanarunsawat, T., Devakul Na Ayutthaya, W., Songsak, T., Thirawarapan, S. and Poungshompoo, S. (2011). Lipid-lowering and antioxidative activities of aqueous extracts of Ocimum sanctum L. leaves in rats fed with a high-cholesterol diet. Oxidative Medicine and Cellular Longevity, 2011, 962025. https://doi.org/10.1155/2011/962025

Thakur, L., Ghodasra, U., Patel, N. and Dabhi, M. (2011). Novel approaches for stability improvement in natural medicines. Pharmacognosy Reviews, 5(9), 48-54. https://doi.org/10.4103/0973-7847.79099

Tran, T.T.-D., Tran, P.H., Khanh, T.N., Van, T.V. and Lee, B.-J. (2013). Solubilization of poorly watersoluble drugs using solid dispersions. Recent Patents on Drug Delivery and Formulation, 7(2), 122-133. https://doi.org/10.2174/1872211311307020004

Upadhyay, A.K., Chacko, A.R., Gandhimathi, A., Ghosh, P., Harini, K., Joseph, A.P., Joshi, A.G., Karpe, S.D., Kaushik, S. and Kuravadi, N. (2015). Genome sequencing of herb Tulsi (Ocimum tenuiflorum) unravels key genes behind its strong medicinal properties. BMC Plant Biology, 15, 212. https://doi.org/10.1186/s12870-015-0562-x

Upadhyay, R., Nachiappan, G. and Mishra, H.N. (2015). Ultrasound-assisted extraction of flavonoids and phenolic compounds from Ocimum tenuiflorum leaves. Food Science and Biotechnology, 24, 19511958. https://doi.org/10.1007/s10068-015-0257-y

Wang, D., Li, H., Gu, J., Guo, T., Yang, S., Guo, Z., Zhang, X., Zhu, W. and Zhang, J. (2013). Ternary system of dihydroartemisinin with hydroxypropyl- $\beta$ cyclodextrin and lecithin: simultaneous enhancement of drug solubility and stability in aqueous solutions. Journal of Pharmaceutical and Biomedical Analysis, 83, 141-148. https://doi.org/10.1016/ j.jpba.2013.05.001

Wang, X., Luo, Z. and Xiao, Z. (2014). Preparation, characterization, and thermal stability of $\beta$ cyclodextrin/soybean lecithin inclusion complex. Carbohydrate Polymers, 101, 1027-1032. https:// doi.org/10.1016/j.carbpol.2013.10.042

Yousaf, A.M., Malik, U.R., Shahzad, Y., Mahmood, T. and Hussain, T. (2018). Silymarin-laden PVP-PEG polymeric composite for enhanced aqueous solubility and dissolution rate: Preparation and in vitro characterization. Journal of Pharmaceutical Analysis, 9(1), 34 - 39. https://doi.org/10.1016/ j.jpha.2018.09.003

Yuvaraja, K. and Khanam, J. (2014). Enhancement of carvedilol solubility by solid dispersion technique using cyclodextrins, water soluble polymers and hydroxyl acid. Journal of Pharmaceutical and Biomedical Analysis, 96, 10-20. https:// doi.org/10.1016/j.jpba.2014.03.019

Zhao, Y., Sun, C., Shi, F., Firempong, C.K., Yu, J., Xu, $\mathrm{X}$. and Zhang, W. (2016). Preparation, characterization, and pharmacokinetics study of capsaicin via hydroxypropyl-beta-cyclodextrin encapsulation. Pharmaceutical Biology, 54(1), 130138. https:// doi.org/10.3109/13880209.2015.1021816 